\title{
FRAMEWORK FOR TEACHING PARALLEL FLIPPED CLASSROOMS
}

\author{
Ioana Rontu, Mohammed Moshirpour, Sepideh Afkhami Goli, Fatemeh Sharifi and Ehsan Mohammadi \\ University of Calgary \\ irontu@ucalgary.ca, mmoshirp@ucalgary.ca, sepideh.afkhamigoli@ucalgary.ca, fatemeh.sharifi1@ucalgary.ca, \\ emohamma@ucalgary.ca
}

\begin{abstract}
Advancements in information technology has given rise to a new flipped learning environment that is increasingly used at post-secondary institutions. This new pedagogical approach provides a personalized learning experience by accommodating different students' learning styles. Students interact with the course material prior to attending scheduled face-to-face instruction, where learning is reinforced by working through examples and application problems. This paper provides a practical guiding framework for the collaboration and coordination of multiple instructors in a flipped delivery course style, based upon a literature review, qualitative research, and experience. We used a qualitative approach using a questionnaire to gather lessons learned and suggestions from instructors. The responses were analyzed to extract common themes which were mapped to create a conceptual framework for successful multi-instructor flipped course delivery. Recommendations are made as per three chronological sequences of before, during and after the course offering. The framework aims to support the planning, implementation and evaluation stages of organizing and managing a multi-instructor flipped course. This paper stresses the importance of the teaching team proactively completing the planning and design of course components before the start of the course. Quantitative student feedback received from the fall 2018 course offering in Schulich School of Engineering at the University of Calgary is used to support the flipped classroom delivery, multi-instructor delivery style.
\end{abstract}

Keywords: flipped learning, multi-instructor classroom/teaching, teaching framework, post-secondary introduction programming course, engineering, large class enrollment.

\section{INTRODUCTION}

Post-secondary institutions strive to enhance the overall quality of the education they provide through the use of effective teaching and learning methods, tools, and experiences. Technology advancements have created the opportunity to effectively integrate technology in education by creating flipped classroom environments for students to thrive in. Flipped classrooms, inverted classrooms or blended learning are terms widely used with different meaning and methods of implementation [1]. At its core, flipped learning is the concept of removing instructor-led teaching and replacing it with student-led activities during the class time [2]. Prior to attending class, students are expected to complete a modified lecture component to familiarize themselves with the material. This can be done using various approaches such as completing assigned readings or slides, watching online videos or listening to podcasts or narrated presentations [3]. One of the most popular methods of delivering preclass content is to have students watch online videos before class, followed by completing a short assignment or quiz. This first task shifts passive learning to outside the classroom and makes the students take on an active role. It allows the instructor to use the class time to engage students in problem solving activities and examples [4], leading to a higher level of concept mastery.

This paper will regard flipped learning as the pedagogical teaching method, where students engage in interacting with the course material in an online manner prior to attending class. The method shifts the learning process from being teacher driven to being led by the students. Face-to-face sessions between students and professors are focused on solidifying learning through examples, demonstrations, interactive activities, and class discussions.

In recent years, this new teaching method has gained popularity at post-secondary institutions, where generally courses are offered in multiple sections taught by several instructors to accommodate a large number of students. The flipped classroom model shifts the timing of the instructor's effort put into the course from throughout the semester, to happening before the course start or earlier on. This shift combined with the need to coordinate multiple instructors can prove to be a challenge in delivering courses. The existing challenges call for a best practices framework to be created to help with the delivery of multiinstructor flipped courses.

\section{LITERATURE REVIEW}

\subsection{Flipped Learning}

An increasing number of research papers have been published in the last few years summarizing observations 
of flipped learning such as effectiveness, student experience, advantages and challenges [5]. Well-known advantages of the flipped method include allowing students to learn at their own pace by engaging with technology [4], increased flexibility, customization and accessibility [6]. Some have found that the grading time is reduced, while feedback and turnaround time is increased [7]. With large course offerings where there are multiple instructors and sections, it has been argued that the flipped course delivery style can ensure a certain level of consistency in the breadth and depth of the course material taught [8]. Moreover, it has been suggested that pre-recorded lectures can reduce lecturing time by helping instructors stay on track due to having a time constraint [3].

With this new method, there are also challenges that have been identified such as the increased time and effort needed for instructors to invest prior to the course offering to create the course material [3]. Likewise, it has been noted that this reduces an instructor's spontaneity during lectures while creating a delay in answering students' questions and increasing the effort on the students' side by requiring them to note down questions and ask at a later time [3]. In addition, some instructors find it challenging to re-design a course while maintaining their current workload [8]. The large initial time investment can be a deterrent for instructors. However, it should be noted that the course material can often be re-used with minimal updates in future course offerings.

\subsection{Parallel Teaching}

At certain post-secondary institutions, each course is offered in multiple class sections to accommodate a large number of interested students. This was defined as "parallel teaching" by Rex Ennis in 1986 [9]. Often times, each instructor is responsible for teaching and examining their own class section and no collaboration with other sections' instructors is needed. This can lead to inconsistencies in the breadth and depth of concepts taught among the multiple class sections, as noted in a paper published by the Georgia Institute of Technology in a study conducted prior to implementing a flipped learning environment in their introductory circuits class [8]. At other institutions, such as at the Schulich School of Engineering, University of Calgary, it is common for the instructors to collaborate on deciding on the syllabus, class structure, examination tools, content and grading, which results in a modified parallel teaching method. From an instructor's perspective, working together with other instructors can help share the responsibility of designing and teaching a course [10]. This can provide a more manageable teaching load for all instructors involved. These two examples illustrate two opposite methods of delivering courses with high enrollment numbers. However, there are multiple flavors of instructor collaboration across multiple class sections. These can range from one instructor designing the course material and trajectory with additional instructors delivering the content, or to all instructors designing and delivering the same course content. Likewise, student examination material and grading can be different for each section and decided upon by each instructor independently or be standardized across all course sections.

Several studies identified the benefit of having multiple instructors as being beneficial to the students to gain exposure to different viewpoints and methods of teaching [10]. Furthermore, multiple instructors can bring a diverse perspective to the material and examples presented in the course and can provide students with additional help with course material [11]. At the same time, it has been found that working together with other instructors to make decisions regarding course components and student concerns has prompted instructors to make more thoughtful and clear decisions [11].

Nevertheless, the need to coordinate and collaborate with multiple instructors can cause certain challenges. One of the papers reviewed has identified that different teaching philosophies can cause friction during the course implementation stage [11]. Another challenge is the lack of coordinated communication regarding course content between instructors [11]. The study suggested that professors attend each other's sections to understand how the material is taught [11].

Often instructor teams are put together for various reasons and the need to effectively translate instructors' distinct identities to a team environment is challenging. It is important to mitigate power imbalances in teaching teams due to age, experience, gender, race, seniority, as these can affect the dynamics between instructors and also instructors and students [11].

The nature of offering a flipped course with multiple instructors requires thoughtful and careful planning before the course offering to ensure a successful implementation.

\section{CASE STUDY CHARACTERISTICS}

The Schulich School of Engineering at the University of Calgary offers a mandatory introductory programming course, ENGG 233: Computing for Engineers, to first-year students. In recent years, the faculty has chosen to switch the course delivery to a flipped classroom style to provide the $800+$ students taking the course every fall semester with increased opportunity to interact with professors [12] [13]. The course entailed students watching approximately 100-minute YouTube videos per week prior to attending two in-person sessions: a 75-minute tutorial and a 110minute laboratory. The approximate 100-minute weekly videos cover the same amount of content, as 150-minutes of in-person lectures. This efficiency was achieved online due to reducing in-person tasks that occur when teaching a lecture in person, such as writing out the lecture notes by hand and erasing the boards. Students were divided into four sections where one instructor overlooked one tutorial 
and laboratory section. During each tutorial, instructors worked through code examples. During the laboratory, students were expected to work through and submit in-lab assignments by the end of the class. These in-lab assignments were released a few days in advance of the lab session. In addition, post-lab assignments were to be submitted one week after the laboratory session. Finally, certain laboratory sessions were used for students to work on their term project.

A small percentage of students' grades came from completing weekly online quizzes, associated with YouTube videos posted. Students from all four sections of the course wrote identical midterms and finals concurrently. This course was delivered by four instructors, twenty-eight teaching assistants (TA's) and four TA coordinators.

Instructors teaching this course met on a weekly basis to coordinate and plan for upcoming course tasks. Furthermore, each week one of the four instructors took on the task of designing the upcoming week's assignments (pre-lab \& post-lab). Email was extensively used among the instructors to communicate.

\section{METHODOLOGY}

This paper uses a qualitative approach with a questionnaire instrument to gather lessons learned and suggestions for improvement from instructors who taught the flipped course. The instructors were asked to comment on several course aspects to identify challenges faced within a multi-instructor flipped classroom. Professors answered questions with regards to challenges faced while delivering certain course components, as well as content and organization.

The questionnaire was administered after the course offering and the responses were analyzed for common themes. The themes were mapped to create a conceptual framework for successful multi-instructor flipped course delivery.

Three out of the four instructors filled out the survey. The fourth instructor was interviewed and provided verbal insight into the course. Furthermore, literature research on flipped classrooms and multi-instructor course offerings was used to further enhance the framework proposed. The lessons learned, and best practices were gathered from multiple papers published on the topic of post-secondary education.

At the same time, a quantitative student survey was administered for the fall 2018 course offering and used to support the flipped classroom delivery, multi-instructor delivery style.

\section{RESULTED FRAMEWORK}

The framework proposed is to be implemented in three periods, namely pre-course start date, during the course offering and post course completion. The framework focuses on addressing key items before the course offering to help instructors be proactive rather than reactive during the semester.

\subsection{Pre-Course Delivery}

Instructors who are new to flipped learning should be first introduced to the concept through a presentation by an individual who is familiar with the method. It is important for instructors to understand the benefits of the method and the challenges that they may face to better prepare them for implementation

Before the team dives into discussing course-related matters, the instructional team should get to know each other's backgrounds, teaching philosophies and general working habits. It is recommended that time is set aside at the beginning of the first meeting, to appropriately introduce all members. A great questionnaire to help instructors understand each other's approach to a course is introduced in [11] by the researchers at the Center of Research on Learning an Teaching at the University of Michigan.

Below are a few suggested topics to be discussed and decided upon at the first meeting:

- Establish a common manner of how instructors will be addressed by fellow team members and students to mitigate power imbalances [11].

- Discuss how decisions will be made within the instructional team.

- Create a clear conflict resolution strategy on how the team will deal with conflict.

- Identify internal and external resources available to the teaching team. This may be in the form of a senior instructor within the team, support available from colleagues outside of the team or instructors who have previously taught the course. Some institutions also have a teaching and learning center that can provide support.

- Discuss responsibilities and expectations within the team regarding communication methods, frequency and shared workload.

The following topics should be discussed and decided upon before the course start:

- Course content and any changes sought by each member.

- Course components such as assignment(s), laboratories, tutorial sessions, class participation, term project(s) and examination(s). Along with marking rubrics and grading criteria for each course components. The process of designing the content of these components, timelines and person(s) responsible should be discussed in advanced.

- Timeline of when course components such as assignments and laboratories will be made available to students. 
- Establish which team member(s) will address student conflicts and grade complaints [11].

If possible, it is recommended that prior to the course start instructors receive course notes from previous course offerings and recorded lectures so that they can better prepare.

\subsection{During Course Delivery}

Based on the survey implemented as part of this study, it was found that a one-hour weekly meeting helped the team address concerns and stay on track throughout the semester. It is recommended that teams schedule meetings at mutually agreeable times, where all members can attend regularly and that an agenda is used to ensure structure and effectiveness. One member of the team should be responsible for leading the discussion and minding the time limit. A possible weekly agenda outline is suggested below:

- Team updates - where all members provide a short (maximum 3 minute) update to the rest of the team.

- Challenges \& solutions discussion.

- Upcoming deliverables discussion and task division.

- To do list \& upcoming deadlines.

It is also recommended that throughout the course offering a central bank is created and constantly updated to store effective codes, helping current and future instructors.

\subsection{Post Course Delivery}

After the course offering, to facilitate the transfer of lessons learned and best practices, the following are suggested:

- Compile all course material such as lectures, tutorials, laboratories, examples and other relevant course material to be easily shared with future instructors.

- Seek feedback from both instructors and students on course content and delivery method to facilitate further improvement to the course offering. This information should be tracked and passed along to the next teaching team.

- Before the next course offering, conduct a transition meeting with the new teaching team to facilitate any further transfer of information.

\section{DISCUSSION}

\subsection{Survey Instrument Themes}

The instructor questionnaire administered as part of this study, indicates that instructors who taught ENGG 233 in fall 2018, mainly had challenges with designing and selecting appropriate weekly tutorial examples that bridged the gap between the basic concepts covered in the online videos and the required in-lab assignments that students needed to complete. Furthermore, it was noted that accomplishing this task within the 75-minute tutorial section made it crucial for instructors to be well organized and prepared. Similarly, one instructor has mentioned that designing the course project during the course offering was challenging, as they also had to manage the teaching demand. In addition, instructors mentioned that designing test questions for the examinations was challenging in ensuring all concepts are tested at an appropriate depth. Creating or narrowing down tutorial questions and designing the term project are examples of tasks that can be done prior to the course offering with appropriate planning. Another challenge that all instructors noted was that it was tough to accommodate students during the inperson tutorials who did not watch the online videos and were not familiar with the basic concepts.

All instructors agree that the expertise of the seasoned instructor who has taught this course before has greatly helped in selecting appropriate tutorial examples and finding effective teaching methods to relay the information to students. All instructors acknowledged that collaborating with other instructors has brought on new ideas and more diverse application engineering examples.

\subsection{Student Feedback Survey}

After the ENGG 233 course offering in fall 2018, a survey was administered to students to gauge perspective on the course. A total of 512 responses were received from across all four-course sections. The results of this student survey show that the teaching team was able to deliver a seamless course offering between all four sections with an online and in-person portion. Figure 1 shows that over $61 \%$ of students indicated that they prefer online lectures to inperson tutorials, which supports the flipped model.

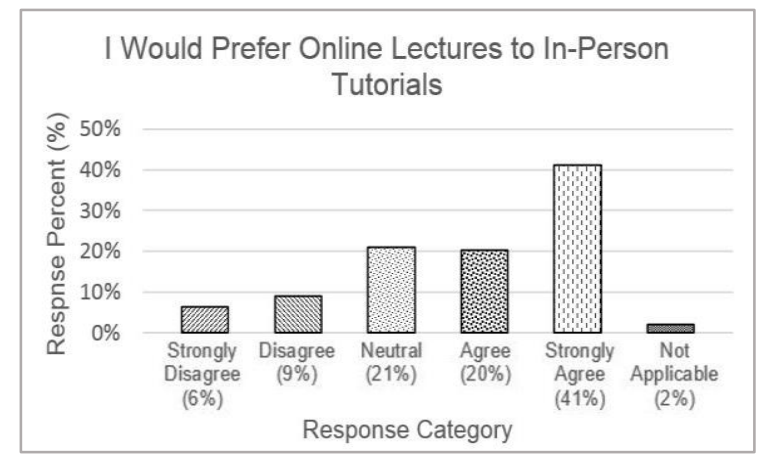

Fig. 1. The distribution of students preferring online lectures over in-person tutorials.

Figure 2 shows that an overwhelming $84 \%$ of students indicated that the online lectures were helpful. While Fig. 3 , shows that $59 \%$ of students found that the in-person tutorials were helpful. 


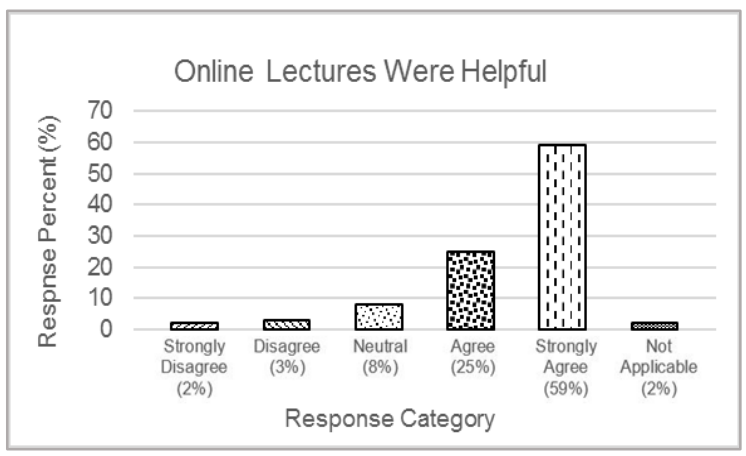

Fig. 2. The distribution of students' satisfaction with online lectures.

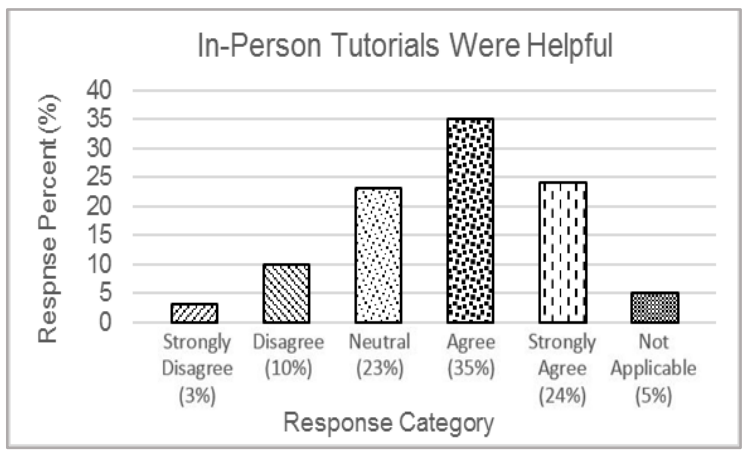

Fig. 3. The distribution of students' satisfaction with inperson tutorials.

The positive student feedback to the flipped, multiinstructor course delivery style supports that the method is effective and even preferred by students.

\section{CONCLUSION}

Flipped learning is gaining popularity among course offerings at post-secondary institutions and it is increasingly used to deliver courses to large numbers of students taking introductory classes. This entails the need to have a team of instructors work together to deliver the course. An extra layer of difficulty is added when the course is offered in a flipped learning environment and instructors need to coordinate appropriately to ensure that the course is delivered effectively. This study investigated existing best practices with respect to delivering flipped courses and effectively working together as a team of instructors, known as parallel teaching. A recommended framework was put together based on literature research, surveyed instructors and their experience. It is recommended that instructors discuss and complete most course related tasks in the planning stage before the course starts, to shift from a reactive approach to a proactive one. The ENGG 233 multi-instructor, flipped learning model is supported by student feedback collected at the end of the semester.

\section{References}

[1] M. Driscoll, "Blended Learning: Let's Get Beyond the Hype," E-Learning, vol. 3, no. 3, 2002.

[2] R. Pierce and J. Fox, "Vodcasts and Active-Learning Exercises in a 'Flipped Classroom' Model of a Renal Pharmacotherapy Module," Am. J. Pharm. Educ., vol. 76, no. 10, 2012.

[3] S. Arnold-Garza, "The Flipped Classroom Teaching Model and Its Use for Information Literacy Instruction," Commun. Inf. Lit., vol. 8, no. 1, pp. 7-22, 2014.

[4] J. O'Flaherty and C. Phillips, "The Use of Flipped Classrooms in Higher Education: A Scoping Review," Internet High. Educ., vol. 25, pp. 85-95, 2015.

[5] G. Akçayır and M. Akçayır, "The Flipped Classroom: A Review of its Advantages and Challenges," Comput. Educ., vol. 126, no. July, pp. 334-345, 2018.

[6] D. O. Bruff, D. H. Fisher, K. E. McEwen, and B. E. Smith, "Wrapping a MOOC : Student Perceptions of an Experiment in Blended Learning," MERLOT J. Online Learn. Teach., vol. 9, no. 2, pp. 187-199, 2013.

[7] R. D. Arasasingham, I. Martorell, and T. M. Mcintire, "Online Homework and Student Achievement in a Large Enrollment Introductory Science Course," J. Coll. Sci. Teach., vol. 40, no. 6, pp. 70-79, 2011.

[8] B. Ferri, J. Harris, M. A. Weitnauer, and D. Majerich, "A Feedback-Based Approach for Evolving a Blended Class Model for Large Enrollment, Multiple Section Circuits Courses," in Proceedings - Frontiers in Education Conference, FIE, 2015.

[9] R. Ennis, "Team Teaching in Adult Basic Education," Aust. J. Adult Educ., vol. 26, no. 3, pp. 4-8, 1986.

[10] B. C. . A. O. Collins, "Using Team Teaching To Deliver Coursework Via Distance Learning Technology," Teach. Educ. Spec. Educ., vol. 19, no. 1, pp. 49-58, 1996.

[11] D. Meizlish and O. Anderson, "Teaching in Teams: A Planning Guide for Successful Collaborations," University of Michigan, Center for Research on Learning and Teaching (CRLT), 2018.

[12] E. A. Marasco, M. Moshirpour, L. Behjat, M. Moussavi, and Y. Amanneja, "Evidence-Based Best Practices for First-Year Blended Learning Implementation," ASEE Annu. Conf. Expo. Conf. Proc., vol. 2018-June, 2018.

[13] E. A. Marasco, M. Moshirpour, and M. Moussavi, "Flipping the Foundation: A Multi-Year Flipped Classroom Study for a Large - Scale Introductory Programming Course," ASEE Annu. Conf. Expo. Conf. Proc., vol. 2017-June, 2017. 